\title{
Modernidades en las Américas: de las vanguardias a la actualidad
}

Fiona McMahon y Paul-Henri Giraud

Traductor. Marta Gómez

\section{OpenEdition}

1 Journals

\section{Edición electrónica}

URL: https://journals.openedition.org/ideas/3131

DOI: 10.4000/ideas.3131

ISSN: 1950-5701

\section{Este artículo es una traducción de:}

Modernités dans les Amériques : des avant-gardes à aujourd'hui - URL : https://

journals.openedition.org/ideas/2544 [fr]

Otras traducciones del artículo:

Modernities in the Americas: from the avant-gardes to nowadays - URL : https://

journals.openedition.org/ideas/3125 [en]

As modernidades nas Américas: desde as vanguardas até hoje - URL : https://

journals.openedition.org/ideas/3151 [pt]

\section{Editor}

Institut des Amériques

Referencia electrónica

Fiona McMahon y Paul-Henri Giraud, «Modernidades en las Américas: de las vanguardias a la actualidad», IdeAs [En línea], 11 | 2018, Publicado el 21 junio 2018, consultado el 19 octubre 2022. URL: http://journals.openedition.org/ideas/3131 ; DOI: https://doi.org/10.4000/ideas.3131

Este documento fue generado automáticamente el 19 octubre 2022.

\section{c) (†) $\odot$}

Creative Commons - Atribución-NoComercial-SinDerivadas 4.0 Internacional - CC BY-NC-ND 4.0 https://creativecommons.org/licenses/by-nc-nd/4.0/ 


\title{
Modernidades en las Américas: de las vanguardias a la actualidad
}

\author{
Fiona McMahon y Paul-Henri Giraud
}

Tradución : Marta Gómez

1 Replantear hoy en día la cuestión de la modernidad -literaria, artística, social o política- equivale a emplear la palabra en plural. Esta decisión supone no limitarse al término polisémico, y a menudo ambiguo, de modernismo. Este último, que con frecuencia se invoca para designar el imaginario cultural de la modernidad, apenas sirve para dar cuenta de las diferencias que se manifiestan en la manera de concebir la relación con el tiempo, la historia y la cultura. «La modernidad no es un movimiento como el dadaísmo o el imagismo. Si la historia literaria decide dar a movimiento, inglés o español, el nombre de modernismo, el término adquiere enseguida un sentido técnico. Se consolida y ya solo participa de la modernidad de una forma fragmentaria» (Meschonnic H., 1988: 26). El concepto de modernidad, a raíz de sus variantes europeas surgidas en el umbral del siglo veinte -tecnológicas, políticas, artísticas-, está marcado igualmente por la disparidad de experiencias en los distintos lugares y espacios de las Américas. El presente número de la revista IdeAs busca poner en perspectiva este concepto en el ámbito de las artes y la literatura a partir del momento clave de las vanguardias nacidas de la Primera Guerra Mundial. ¿Qué repercusiones tuvieron en las Américas las transformaciones culturales introducidas en Europa y, a la inversa, qué formas de resistencia iluminan las producciones americanas?

2 Se trata por tanto de reexaminar un fenómeno multiforme y multilingüe con el fin de extraer las líneas maestras o divisorias. Para las distintas áreas culturales de las Américas, ¿qué horizontes ofrece el paradigma a la vez destructor y creador de la modernidad? «En nombre de la radicalidad artística y del concepto de ruptura», se han «dejado de lado o subestimado numerosas expresiones individuales o colectivas consideradas híbridas, locales, tardías o antimodernas», podemos leer sobre el arte (Grenier C., 2013: 16). De igual modo, en literatura seguimos midiéndonos respecto al modelo del eterno porvenir del pasado: «Hay que ser antiguo para tener alguna posibilidad de ser moderno o de decretar la modernidad» (Casanova P., 2008: 137). De 
ahí la búsqueda sistemática de ancestros de lo moderno, incluso en los mundos llamados «primitivos» o indígenas. Por retomar e invertir la antítesis clásica planteada por el argentino José Domingo Sarmiento (2006) a mediados del siglo XIX, a menudo la «barbarie» parece más moderna que la «civilización» siempre y cuando se sepa evitar la tentación folclorista, algo que intentan hacer las estilizaciones de lo moderno cuando se aplican al material vernáculo.

3 Las diferencias innegables, así como las coincidencias entre las Américas anglófona e hispanófona -lamentamos que las áreas francófona y lusófona no hayan podido ser representadas en este número- deberían permitir comprender mejor las especificidades de cada una de estas regiones y sus propios contrastes internos desde las primeras décadas del siglo XX hasta el periodo actual. Porque solo hoy las modernidades sucesivas encuentran a la vez su forma exacta y su respuesta tanto en los replanteamientos operados por el pensamiento poscolonial y decolonial como en ciertas extensiones de las artes, la literatura, incluso la etnología.

\section{Pintura, fotografía y danza}

4 La vanguardia de principios del siglo XX, marcada por la sucesión de «-ismos», desarrolla activamente la utopía de mezclar y hacer converger las artes. En México, dentro de la efervescencia cultural que siguió a la Revolución, la literatura, la pintura, el grabado, la fotografía y los caligramas convergieron en la revista Irradiador (1923), que en su subtítulo se definía como «Revista de vanguardia, proyector internacional de nueva estética». Según Isabelle Pouzet, el culto a lo nuevo, el rechazo agresivo de lo antiguo, la valorización estética de lo arbitrario y lo fragmentario, la poesía caótica de la ciudad moderna definen la esencia del efímero movimiento «estridentista» del que esta revista se hizo portavoz. En la portada del tercer número, una fotografía de Edward Weston tomada en 1922 en Ohio, titulada Steel, muestra una fila de chimeneas de fábrica en contrapicado. Esta detonante introducción de una imagen bruta y estilizada de la industria estadounidense en la primera página de Irradiador marca el advenimiento en México de la llamada "Fotografía directa" (Straight Photography) y manifiesta la fuerte aspiración a la modernidad de los artistas de este país, impulsada por el gran vecino del Norte. La estancia de Weston en México entre 1923 y 1926 fue el nexo entre las vanguardias al norte y al sur de Río Grande.

5 A la euforia iconoclasta de Irradiador, cuyo entusiasmo militante y ecuménico casi podría calificarse de ingenuo, siguió, con la institucionalización de la Revolución mexicana, una utilización más crítica del medio fotográfico. Contra la «mitología de un modernismo triunfante», en discrepancia con la «escenificación nacionalista en la cultura visual» que la pintura muralista o la escultura a la gloria del régimen llevaron a cabo durante los años 1920-1930, Erica Segre detecta en la fotografía mexicana contemporánea, en particular en Agustín Jiménez, una «vertiente reflexiva atormentada por el encuadre y el poder coercitivo profundo». La autora se afana en dar a conocer las «estéticas disidentes» que, mediante un juego de sombras y rejas, sugieren el encierro de los mexicanos en un unanimismo nacional. Al principio subterránea, esta sorda «indisciplina» fotográfica solo se hace patente en los años 1950-1960 en las fotos de Nacho López, Rodrigo Moya o Héctor García. Los retratos que este último realizó del pintor David Alfaro Siqueiros (1896-1974) entre rejas en la cárcel de Lecumberri a principios de los años 60 hacen de este artista marxista un verdadero 
icono. Para Siqueiros, ser moderno implicaba poder circular entre las condiciones antinómicas de pintor de vanguardia, pintor oficial y paria, a través de la performance interrumpida de su gesta político-artística. El muralista, que nunca dejó de rechazar la pintura de caballete logró, a pesar de todo, no salirse nunca del «marco» mediático, y ello, gracias al encuadre fotográfico.

6 Su coetáneo estadounidense Stuart Davis (1892-1964) ofrece un caso muy diferente. Kamila Benayada ve en su trabajo una «redefinición del modernismo» a través de «la serie los Champion, pintada durante la Guerra Fría». Si la construcción de la obra de arte se basa en la relación que mantiene con el mundo, la práctica de Davis consiste en complicar los términos de esa relación creando un diálogo con sus propias obras anteriores, así como con las de sus predecesores modernistas, y ampliando la esfera artística al entorno visual de la cultura popular. La transitividad de la obra pintada vincula los gestos pictóricos al mundo y a sus contextos semióticos. Convertida en visible en la superficie del lienzo, la relación del artista con su tiempo sustenta un dispositivo de invención pictórica que, ignorando las fronteras genéricas, celebra el movimiento y el intercambio.

7 Elsa Crousier, por su parte, rastrea la evolución de la crítica de arte de origen uruguayo Marta Traba, fundadora en 1963 del Museo de Arte Moderno de Bogotá. Tras sostener un discurso internacionalista y cosmopolita sobre el arte, a partir de los años 60, Traba se centra en definir el arte latinoamericano contra el Norte (Europa pero aún más Estados Unidos). Según ella, la «resistencia» latinoamericana pasaba por un rechazo a los tópicos superficialmente modernos del Pop Art y por la inmersión en la identidad regional y la psique amerindia. Por tanto, para ser modernos, los artistas latinoamericanos debían, de algún modo, hacerse antimodernos.

8 Con Claudie Servian podemos observar cómo la modernidad y la descentralización cultural a la que esta da lugar conducen a una metamorfosis del paisaje coreográfico estadounidense en los albores del siglo veinte. En los escritos teóricos de las coreógrafas Martha Graham (1894-1991) y Doris Humphrey (1895-1958) analizados aquí, la búsqueda de la modernidad implica un descubrimiento del pasado más antiguo. El fantasma del origen, unido al rechazo del modernismo tecnológico, lleva a la danza a explorar los arcaísmos perdidos, enterrados en el inconsciente o identificados con modelos tomados de las culturas amerindias. El retorno a las artes tribales y al psiquismo primitivo enfrenta el mecanismo de la modernidad a los movimientos del cuerpo en lo que estos tienen de intuitivo y natural. La modernidad del cuerpo dependería por tanto de su potencial expresivo y significante en una relación de contacto o de comunión con su entorno. La interacción con el suelo sería la garantía de una creación auténtica, al tiempo que hace emerger los decorados de la historia americana, como en algunas coreografías de los años 30. Así, la ruptura con la tradición académica europea pasa por el mito de la vuelta a los orígenes.

Un movimiento similar se observa en América Latina en los años 60 en torno a la noción de neobarroco que estudia Marcos Rico Domínguez. El arte colonial hispanoamericano llevó a cabo la síntesis de las civilizaciones prehispánicas y el catolicismo español. La categoría estética barroco, inventada a finales del siglo XIX, pero sobre todo teorizada en la primera parte del siglo XX, fue reivindicada en los años 60 por un grupo de autores cubanos y analizada por el mexicano Octavio Paz (1914-1998) como uno de los fundamentos de la modernidad latinoamericana. Paz operaba así la confluencia entre la época histórica llamada «moderna» (siglos XVI-XVIII) 
-apogeo del Imperio Hispánico, rico en abundantes semillas- y la desconcertante proliferación de signos en la vanguardia de los años 60 , destacando el sustrato indígena de un arte en apariencia muy occidental y «moderno».

\section{Novela y poesía}

10 Mientras las modernidades americanas en su dimensión estética apuntan tradicionalmente a la experimentación formal de los artistas y autores de las primeras décadas del siglo XX y a su relación con la vanguardia europea, Céline Mansanti nos invita a dejar de lado los discursos contestatarios y a reflexionar sobre la relación entre el modernismo literario angloamericano y la llamada literatura mainstream del periodo de entreguerras, que actualmente es objeto de reevaluaciones críticas. En su artículo titulado «Más allá de los clichés y la sátira: el debate sobre la expatriación y el modernismo en la novela mainstream "The French They are a Funny Race" de Lyon Mearson (1931)», Mansanti plantea el tema del contexto de producción de una obra poco estudiada para descubrir puntos de convergencia de influencias entre, por un lado, el escenario modernista en el que transcurre la vida de los expatriados en París campo de experimentación reflexivo que problematiza las convenciones discursivas de la literatura-y, por otra, la cultura middlebrow o «media», donde la transparencia de los universos ficticio y estilístico participa de las reglas de la sociedad de consumo emergente.

11 En el artículo «Bill \& Carlos: las Américas de William Carlos Williams», Anna Aublet arroja nueva luz sobre la especificidad sociocultural de la obra del poeta William Carlos Williams (1983-1963), y sobre la doble identidad lingüística y cultural de este autor estadounidense de madre puertorriqueña. Tomando como punto de partida el marco polémico de la modernidad poética, la reflexión gira en torno a la reconquista por parte de la poesía de la historia y los mitos del continente americano que, en el caso de Williams, está basada en operaciones paradójicas de deconstrucción y construcción. Aublet estudia la revisión de los mitos fundadores de la historia americana que Williams lleva a cabo en sus obras novelescas de los años veinte The Great American Novel (1923) y In the American Grain(1925). El retorno del autor a sus raíces hispanohablantes forma parte de una búsqueda identitaria individual y colectiva que atraviesa todo el continente de norte a sur. El descifrado de los códigos semánticos propios de Williams va unido a la hipótesis de una lengua vernácula, democrática pero dispar, nacida del mestizaje. Los horizontes de la novedad, objeto de una búsqueda obsesiva en este poeta, se abren así a la lengua española, herencia materna y vestigio del pasado colonial de las Antillas.

La relación con el pasado y los orígenes en la literatura norteamericana es el tema central del artículo de Aurore Clavier «Nuevos contornos sugeridos por viejas palabras: la modernidad estadounidense a través del tamiz de la arqueología poética». La obra de los años 20 de los poetas Wallace Stevens, Marianne Moore y William Carlos Williams está conectada aquí con una doble temporalidad, a la vez retrospectiva y prospectiva. La reflexión de Aurore Clavier se basa en las modalidades arqueológicas de la invención modernista como paradigma de escritura para vincular las exploraciones y excavaciones del pasado con la emergencia de un idioma poético sensible a la dialéctica entre superficie y profundidad, entre las contingencias del presente y el relato original. Si la empresa historiográfica de la modernidad consiste en redefinir los modos de 
reescribir el pasado estadounidense, según Aurore Clavier, la identidad cultural nacional también se refiere a la fascinación que ejercía el tiempo largo en estos poetas. La relación del continente americano con la modernidad debe pues leerse en el reflejo de la actividad mito-poética de estos escritores. El desplazamiento que tiene lugar en relación con los puntos de anclaje es tanto de orden estético como político y geográfico, de norte a sur y de este a oeste. En su enfoque hemisférico, Clavier intenta abarcar la pluralidad involucrada en la empresa de reescribir el origen, a saber, la búsqueda de un presente enraizado en emplazamientos plurales. En Williams en particular, el contexto histórico y social de In the American Grain abarca Centroamérica, el Caribe y las naciones amerindias y permite hacer hincapié en la hipótesis de un modernismo americano que ya no puede concebirse como cultural ni políticamente neutro.

Como recuerda François Hugonnier en su artículo «Repensar los modernismos a la luz de la obra de Jerome Rothenberg», la vanguardia europea había desplazado su foco de atención hacia los márgenes de la práctica artística abriendo así el camino, para la modernidad americana, hacia la heterogeneidad de formas y culturas. La pluralidad demuestra ser uno de los principales resortes del modernismo, proteiforme e internacional. Leer a Rothenberg (nacido en 1931) es descubrir a un defensor de un nuevo escenario de modernismos que tiene en cuenta, más allá de suelo americano, a una miríada de fuentes locales y "globales» de diversas épocas. François Hugonnier destaca el papel de Rothenberg como cartógrafo de una poética comprometida, panamericana y cosmopolita, políglota e iconoclasta. Así, la militancia editorial de Rothenberg hizo realidad el proyecto inédito de leer la modernidad literaria a la luz de textos autóctonos, a menudo traducidos. Este artículo destaca la pertinencia del gesto antológico, recopilador de poesías subrepresentadas o enterradas bajo el manto monolítico del canon occidental en este quincuagésimo aniversario del volumen pionero que fue Technicians of the Sacred: A Range of Poetries from Africa, America, Asia, Europe \& Oceania (1968).

Al final de este recorrido podemos preguntarnos con William Mohr cómo los cambios posmodernos han repercutido en la formación en el continente americano de comunidades heterogéneas implicadas, en calidad de lectores, autores, editores, impresores o críticos, en el mundo de las letras en la época contemporánea. Deseoso de explorar las condiciones sociopolíticas de la producción literaria y teniendo como telón de fondo la trayectoria de su propia obra poética, en su artículo titulado «La Costa Oeste como capital literaria en la república de la literatura: los editores independientes como agentes plásticos de la hipermodernidad», William Mohr parte del modelo teórico llamado «circuito de comunicación» - propuesto por el historiador estadounidense Robert Darnton, especialista de la historia del libro-para abordar la construcción de un canon poético de la Costa Oeste durante los años 1955-1985 gracias a la sinergia editorial de un grupo de poetas y editores independientes. Los esfuerzos colectivos de estos actores culturales permiten entrever un nuevo relato de la (pos)modernidad a la luz de la diseminación cultural. Abrir las líneas de demarcación de un canon poético, como hace la comunidad literaria celebrada aquí por William Mohr, supone participar en los deslizamientos de pensamiento y discurso que, hasta hoy y de diferentes maneras, dan primacía al cambio. 


\section{¿Fuera de Occidente?}

15 La emergencia de la modernidad no puede pensarse sin reflexionar acerca de las articulaciones entre el ámbito artístico y el campo sociopolítico. Por citar de nuevo a Meschonnic, sabemos que las fronteras políticas y territoriales de lo moderno fueron definidas por Occidente: «La modernidad. Huelga decir: 'occidental'. La modernidad es europea. Y si por Occidente entendemos Europa, más América del Norte, [la modernidad] es occidental» (1988: 27). Pero la modernidad se plantea asimismo como «el terreno de un trabajo sobre el sentido» (1988: 26), sujeto a la temporalidad y al espacio en los que todas las sociedades y las culturas evolucionan hoy día. Dentro de este terreno, los estudios de la crítica poscolonial han contribuido a dar a conocer la codificación occidental -europea y americana- que viene a constituir un marco de referencia homogéneo y universal. A través de las formas de resistencia opuestas a la uniformización de los modelos de saber, se dibuja hoy un concepto de «modernidad» en su pluralidad que conviene cotejar con una perspectiva extra-occidental.

Smaro Kamboureli examina así la inscripción de la modernidad en las culturas menoscabadas por Occidente a través del ejemplo de la representación de la cultura inuit en Igloolik, una pequeña comunidad de la región Nunavut en el norte de Canadá. En su artículo titulado «La ópera en el Ártico: Knud Rasmussen, travesías de la modernidad» surge la confrontación dialógica entre dos temporalidades. Entre el testimonio del etnógrafo Knud Rasmussen sobre su experiencia entre los Iglulingmiurt -De Groenlandia al Pacífico: dos años de intimidad con tribus esquimales desconocidas (trad. del danés, 1929) - y la reapropiación de este relato y este momento histórico por la película de Norman Cohn Los diarios de Knud Rasmussen (2006), se perfila la distancia que separa la mirada del etnógrafo sobre la empresa colonizadora y una lectura epistemológica de la cultura inuit en la época contemporánea. La presencia de Occidente en los territorios del norte de Canadá a principios del siglo veinte -al igual que la ópera para los inuits- es la señal para Rasmussen de la «modernidad negativa», un concepto que traduce a su juicio el travestismo de la cultura inuit. La relación con esta época pasada, que en el discurso del etnógrafo viene marcada por la disonancia entre modernidad y alteridad, evoluciona en la película de Cohn hacia una nueva mirada que reconfigura el concepto de «autenticidad» autóctona señalando tanto los límites del régimen colonial como los de la modernidad respecto a la construcción identitaria. El confinamiento en la temporalidad se ve así recusado, y la película invita a leer la cultura autóctona de manera diacrónica, no compartimentada, lejos del mito del origen y del culto a lo «primitivo». En la convergencia entre el archivo occidental y los modos de producción inuit se forma una imagen viva de la experiencia de la alteridad. El relato histórico adaptado por el cine inuit se abre a lo desconocido mostrando la transformación ejercida por el artefacto sobre la experiencia del Otro.

17 Según Susan Friedman, entramos así en el ámbito de la modernidad «relacional» (2015: 28), un modelo sujeto a operaciones de redes en las que se enfrentan alteridades y alteraciones radicales, sin distinción de temporalidad. En la crítica norteamericana, al concepto de modernidad se ha unido el paradigma transnacional para definir las redes de producción cultural y dibujar así una nueva cartografía de lo moderno. La publicación de una teoría diaspórica de la literatura por parte del Institut TransCanada y su directora Smaro Kamboureli va en esa dirección (Scandalous Bodies, 2000). 
Asimismo, para Jahan Ramazani (2009), el debate en torno a la emergencia de una «poética transnacional» revela la amplitud de influencias debida a la porosidad de las fronteras culturales desde las vanguardias y más allá. Desplazando el centro hacia la periferia, esta nueva lectura teórica, construida sobre un modelo de influencia llamado de enredo [«enmeshment»], deja oír las resonancias de la cultura poscolonial en nuestra percepción actual de los sucesivos desarrollos de la modernidad a lo largo del siglo XX y hasta nuestros días.

\section{BIBLIOGRAFÍA}

Casanova, Pascale, La République mondiale des lettres [1999], éd. rev. et corr., Paris, Seuil, « Points Essais », 2008.

Friedman, Susan, Planetary Modernisms: Provocations on Modernity across Time, New York, Columbia University Press, 2015.

Grenier, Catherine, «Le monde à l'envers? », in Modernités plurielles : 1905-1970, Paris, Centre Pompidou, 2013, p. 14-31.

Meschonnic, Henri, Modernité modernité, Paris, Gallimard/Verdier, « Folio Essais », 1988.

Kamboureli, Smaro. Scandalous Bodies: Diasporic Literature in English Canada. Toronto: Oxford UP, 2000.

Ramazani, Jahan, A Transnational Poetics, Chicago, University of Chicago Press, 2009.

Sarmiento, Domingo Faustino, Facundo: Civilización y barbarie [1845], Madrid, Cátedra, « Letras hispánicas ", 2006.

\section{AUTORES}

\section{FIONA MCMAHON}

Fiona McMahon est maître de conférences en littérature américaine à l'Université de Bourgogne Franche-Comté. Ses recherches portent sur le modernisme, les poétiques des $\mathrm{XX}^{\mathrm{e}}$ et $\mathrm{XXI}^{\mathrm{e}}$ siècles (US/CAN), ainsi que sur des relations intermédiales dans les arts et les lettres. Parmi ses travaux sont parus deux monographies : Charles Reznikoff : une poétique du témoignage (L'Harmattan, 2011) et H.D. Trilogy (Atlande, 2013) ; elle a co-dirigé un ouvrage collectif à paraître chez Classiques Garnier en 2018, Penser le genre en poésie contemporaine.Fiona McMahon is Associate Professor of American Literature at the Université de Bourgogne Franche-Comté (Dijon, France). In addition to articles on Modernist and contemporary poetry (US/CAN), and on intermediality in the arts and literature, she is the author of Charles Reznikoff: une poétique du témoignage (L'Harmattan, 2010), H.D. Trilogy (Atlande, 2013) and has co-edited a book of essays, Penser le genre en poésie contemporaine(forthcoming in 2018 with Classiques Garnier). 


\section{PAUL-HENRI GIRAUD}

Professeur en études hispaniques contemporaines à l'Université de Lille, il est directeur adjoint du Centre d'études en civilisations, langues et littératures étrangères (CECILLE) et Secrétaire général de l'Institut des Amériques. Il a publié Octavio Paz: Vers la transparence (2002, édition en espagnol revue et augmentée 2014) et Manuel Álvarez Bravo : L'Impalpable et l'imaginaire (2012). Ces dernières années, il a notamment co-dirigé l'ouvrage 1910: México entre dos épocas (El Colegio de México, 2014) ainsi que deux dossiers monographiques : Fotografía, cultura y sociedad en América latina. Nuevas perspectivas (2015) et Cosmopolitismes dans les Amériques, 1900-1960 (2018), numéros 219 et 223 de L'Ordinaire des Amériques (http://orda.revues.org). paul-henri.giraud@univ-lille3.fr 